\title{
Effect of an Educational Program (PEGASE) on Cardiovascular Risk in Hypercholesterolaemic Patients
}

\author{
Eric Bruckert • Philippe Giral • François Paillard • \\ Jean Ferrières • Jean-Louis Schlienger • \\ Jean-François Renucci • Kamel Abdennbi • \\ Isabelle Durack • Rita Chadarevian • PEGASE group
}

Published online: 2 October 2008

(C) Springer Science + Business Media, LLC 2008

\begin{abstract}
Background Many studies have demonstrated a gap between guidelines for the prevention of cardiovascular disease (CVD) and their implementation in clinical practice. Aim The PEGASE education program has been devised with an aim to improve the management of patients at high risk of CVD.

Methods In a multicentre study carried out from 20012004 in France, 96 participating physicians were randomized into a "trained" group, which included 398 "educated" patients, and a "non-trained" group, which included 242 "non-educated" patients. Educated patients received six hospital-based educational sessions, four collective and two individual. Framingham score, smoking, lipid levels, glycaemia, blood pressure, dietary intake and drug compliance, as well as quality of life, were evaluated at baseline (M0) and 6 months (M6). The primary endpoint of the
\end{abstract}

The study and the PEGASE educational program were supported by AstraZeneca France.

E. Bruckert has received speaker's fees from Astra Zeneca.

E. Bruckert $(\square) \cdot$ P. Giral

Groupe hospitalier Pitié-Salpétrière,

Service d'Endocrinologie-Métabolisme,

47-83, Boulevard de l'Hôpital,

75651 Paris Cedex 13, France

e-mail: eric.bruckert@psl.aphp.fr

F. Paillard

CHU,

Rennes, France

J. Ferrières

CHU,

Toulouse, France

J.-L. Schlienger

CHU,

Strasbourg, France study was the efficacy of the PEGASE program in reducing global CVD risk in high-risk patients.

Results The Framingham score was calculated for 473 patients. The Framingham score improved significantly at M6 vs M0 in the educated group (13.0 \pm 8.21 vs $13.6 \pm 8.48$, $d=-0.658, p=0.016$ ), but not in the non-educated group (12.5 \pm 8.19 vs $12.4 \pm 7.81, d=+0.064, p=0.836)$; the mean change between the two groups did not reach significance. Quality of life, LDL-c level and diet scores improved in the "educated" group only.

Conclusions The PEGASE education program improved risk factors for CVD, although global assessment by Framingham score was not significantly different between groups. This program, aimed at meeting needs and expectations of patients and physicians, was easily implemented in all hospital centres.

Key words Educational program - Cardiovascular prevention · Cholesterol · Framingham score · PEGASE

J.-F. Renucci

$\mathrm{CHU}$,

Marseille, France

K. Abdennbi

$\mathrm{CCN}$,

Saint-Denis, France

I. Durack

Edusanté,

Paris, France

R. Chadarevian

AstraZeneca,

Paris, France 


\section{Introduction}

Cardiovascular disease (CVD) remains a leading cause of death in the world [1]. The proportion of deaths attributable to CVD is increasing; in 2005, 17.5 million people worldwide were estimated to have died from CVD, while the projected figure for 2015 is 20.0 million [2]. In addition, the proportion of patients at high risk of a cardiovascular event in populations previously not known for high rates of CVD, such as Japanese and Indians, is also increasing [3, 4]. Thus, the prevention of CVD via the modification of cardiovascular risk factors is a worldwide concern.

The occurrence of CVD is strongly related to a limited number of potentially modifiable psychosocial and physiological factors [5]. Randomized trials have unequivocally demonstrated that intensive control of multiple risk factors by lifestyle changes and therapeutic interventions substantially reduces cardiovascular mortality and morbidity [6-8]. However, studies such as NHANES, Euroaspire $[9,10]$, and others [11-14] have demonstrated a gap between guidelines for CVD prevention and their actual application in clinical practice. The prevalence of modifiable risk factors was high and the use of drug therapies was inadequate to achieve blood pressure (BP) and lipid goals [14-16], due to insufficient adherence of physicians to guidelines [14], poor long-term compliance of patients with their treatment and/or lifestyle advice [17-19] and difficulty in changing risk behaviours, which have become habits over many years [20].

Hence, improvement of the management of cardiovascular risk factors requires specific intervention such as therapeutic education programs [21]. However, most patients at high risk of CVD are seen in clinical practice within the traditional model of primary care delivery, which often focuses on acute problems [22]. Lack of time, insufficient knowledge and lack of appropriate educational tools are well-known barriers to primary care physicians in providing patients' education [22, 23]. Therapeutic education is a structured, dynamic process involving practical training sessions based on a diverse set of skills and tools, provided by a multidisciplinary team. With this aim, the PEGASE program, an educational program for improved management of high CVD-risk patients, involving the combined training of physicians and education of their patients, has been implemented [24].

We conducted a randomized controlled trial to assess the efficacy of this program at reducing global CVD risk in high-risk patients (primary endpoint).

\section{Methods}

This non-blinded, randomized, multicentre controlled study was conducted according to the Declaration of
Helsinki and the Huriet French law, in 6 French hospital care centres, from December 2001 to March 2004. The study protocol was approved by the ethics committee of the Pitié-Salpetrière hospital (Paris, France). Before enrolment, all participants signed an informed consent form.

Intervention: description of the PEGASE education program

The patients' education program was designed by EDUSANTE Company (Paris). It was derived from the behavioural change model of Prochaska et al. [25], according to the education quality criteria of the World Health Organization [26]. It consisted of six educational sessions provided by an on-site physician (caregiver coordinator) and his team (one nurse and one nutritionist) from six healthcare hospital centres for CVD prevention. Its implementation included a thorough preliminary analysis of the patients' expectations in terms of education and of the physicians' difficulties in delivering their education message [27]. All caregiver coordinators, nurses and nutritionists received training for 2 days on how to use PEGASE education program.

The PEGASE education program has been detailed elsewhere [24]. Briefly, this program used easily understandable, simple methods and materials during four collective and two individual sessions and comprised three stages (increase awareness on CVD risks, start action and maintain action). At the first collective educational session, the Photolanguage ${ }^{\circledR}$ tool was used to help patients identify their own criteria for health and sickness, and which were their major threats. Then they were all invited to create a patchwork figure (using coloured cards) representing an imaginative patient with several risk factors on which they were able to project future CV risks, keeping a distance from their own emotions. During the second and third collective sessions, information about physical activity and healthy diet was given, together with the development of a positive attitude towards a healthy food pattern. This was achieved through educational pamphlets and discussion of clinical cases. Barriers to drug adherence were discussed among groups. At the last collective session, a game with questions and answers mainly focused on cholesterol management helped patients to measure their knowledge. A leaflet with core information was given at the end of each collective session. During the two individual sessions, the caregiver coordinator monitored progress and reinforced educational messages. Individual goals were translated into concrete actions related to diet, physical activity and/ or better treatment adherence. Behavioural change recommendations were broken into small, achievable steps. 
Investigators

Investigators, comprising primary care general practitioners, cardiologists and endocrinologists, were the usual correspondents of the six participating healthcare hospital centres. They were recruited on a voluntary basis from lists established by the centres and were managed by the caregiver coordinator located in one of the participating hospital centres.

\section{Randomization}

Investigators were randomized into two groups, one being subjected to a specific training intervention, the other forming the control group that did not receive any training. Training consisted of an attendance at a half-day workshop on cardiovascular risk factor management and how to increase patients' awareness and motivation. Randomization was performed by simple random sampling. The investigators were randomized rather than patients, to avoid "contamination" of non-educated patients by an attending physician who would initially be trained. The patients included by the "trained physicians" therefore constituted the "educated patient" group and referred to the healthcare hospital centers. The subjects included by the "non-trained physicians" formed the "non-educated patient" group.

\section{Subjects}

To be eligible for enrolment, patients had to fulfil the following criteria: aged 18 years or more, never been followed on a long-term basis by a healthcare centre specialized in patient education, and belonging to one of the three following categories:

Primary prevention:

- Category I: Patients with LDL-cholesterol (LDL-c) levels $>220 \mathrm{mg} / \mathrm{dL}(5.7 \mathrm{mmol} / \mathrm{L})$ before treatment;

- Category II: Patients with LDL-c levels $>160 \mathrm{mg} / \mathrm{dL}$ $(4.1 \mathrm{mmol} / \mathrm{L})$ and $<220 \mathrm{mg} / \mathrm{dL}(5.7 \mathrm{mmol} / \mathrm{L})$ before treatment with at least one of the following cardiovascular risk factors: high BP (BP>140/90 and/or antihypertensive treatment), obesity $\left(\mathrm{BMI} \geq 30 \mathrm{~kg} / \mathrm{m}^{2}\right)$, diabetes (fasting glycaemia $\geq 126 \mathrm{mg} / \mathrm{dL}$ and/or antidiabetic treatment), current smoking, familial history of CVD or HDL-cholesterol (HDL-c) $<35 \mathrm{mg} / \mathrm{dL}$ (0.9 mmol/L).

Secondary prevention:

- Category III: Patients suffering from coronary disease and having an LDL-c level $>130 \mathrm{mg} / \mathrm{dL}$ (3.4 mmol/L) before treatment. If the patient was receiving a lipidlowering therapy, lipid levels before treatment initiation were taken into account.
Patients with language problems and/or with difficulty understanding French, pregnant women or nursing mothers were excluded.

Study design

The primary endpoint of the study was the efficacy of the PEGASE program in reducing global CVD risk. Patients were screened by their primary care physician. Each primary care investigator had to include the first six patients meeting all inclusion/exclusion criteria. Both educated and non-educated groups were followed for 6 months. Participants in both groups attended two visits within the 6month study period and received standard care from their primary physician. In addition, the patients from the educated group were referred to receive the special education sessions during the 6-month period (PEGASE education program) at the centre closest to their residence.

All patients underwent the following: at inclusion (M0), the primary care investigator filled in a medical questionnaire, and at M0 and M6 recorded medical data including BP, biological profile and smoking evaluation. The interpretation of the information collected during consultations was left to the discretion of the primary physicians in the non-educated patient group. Physicians in this group were not given any additional information or training to allow them to interpret the data.

All patients received a prescription for laboratory tests and four auto-questionnaires evaluating quality of life (SF36) [28], pharmacological compliance, physical activity [29] and dietary intake [30].

\section{BP measurement}

BP was always taken using the same arm, with the same measuring apparatus. The first measure was taken for the first time after $5 \mathrm{~min}$ at rest, then twice more with a 2 mininterval. The recorded value was the mean of the last two measures.

\section{Smoking status}

At each visit patients were asked how many cigarettes they smoke per day and for how many years.

All the questionnaires filled in by the patients and physicians were sent back for monitoring and data processing to the company in charge of the database analysis.

\section{Primary outcome}

The efficacy of the education program was assessed by measurement of the global CVD risk defined by the 
modified Framingham Score (Framingham-Anderson model) [31], adapted by Laurier for application to the French population [32]. It is calculated by evaluating smoking and diabetes, BP, HDL-c and total cholesterol (TC) levels. It estimates the risk of CVD incidence over the next 10 years and can be stratified into three categories: $<10 \%$ - low risk; $10-20 \%$ - intermediate risk; and $>20 \%$ - high risk.

\section{Secondary outcomes}

Secondary criteria were dietary and drug compliance, evolution of physical activity, quality of life, smoking, LDL-c and triglyceride levels, glycaemia and BP.

\section{Laboratory tests for biological parameters}

All the laboratory analysis for measurement of TC, LDL-c, HDL-c, triglycerides and fasting glycaemia were centralized in one laboratory (LCL Laboratory, Paris), at M0 and M6. LDL-c was directly measured by an enzymatic colorimetric test in homogenized phase (Roche diagnostics).

\section{Dietary compliance}

Dietary compliance was assessed by the measure of a "cardio-protective" diet score, ranging from -22 to +29 . This score was calculated from a dietary questionnaire which recorded saturated, mono-unsaturated, and polyunsaturated $n-3$ and $n-6$ fatty acid intake as well as fruit, vegetable and wine intake [29].

\section{Physical activity questionnaire}

This questionnaire was adapted from the validated English questionnaire of Norman et al. [29]. The frequency of performing five activities (professional activity, walking/ cycling, housework, TV/reading, physical activities) was evaluated and the number of sleeping hours was recorded with a recall period of 3 months. The score varied from 5 to 27 , the lowest score corresponding to very low activity.

\section{Lipid-lowering drug compliance}

For each drug, the theoretical number of doses to be taken daily was multiplied by 7 , to obtain a theoretical number of doses per week.

To evaluate compliance, the patient calculated the sum of doses taken during the previous week. The drug compliance was then calculated by dividing the sum of doses per week by the theoretical doses number per week, and expressed as a percentage.

\section{Quality of life}

Scores obtained from the SF-36 questionnaire [28] were described for patients having a questionnaire with $<50 \%$ of missing data at M0 or M6. For those presenting a questionnaire with $<50 \%$ of missing data at both visits, quality of life evolution from M0 to M6 was also described.

Statistical analyses

In the absence of reference data about the target population, and with the assumption that to detect a mean difference of $10 \%$ in the total CVD risk score between educated and non-educated groups at 6 months, a sample size of 268 subjects was required in each group to achieve $90 \%$ power at an alpha risk of 0.05 . Taking into account the high risk of patients' withdrawing and being lost for follow-up (33\%), it was necessary to include 360 patients in each group, i.e. a total of 720 subjects to have 600 evaluable patients.

Statistical analysis was performed with SPSS version 11.5 for Windows ${ }^{\circledR}$ software. Quantitative parameters were expressed by number of patients, mean, standard deviation, and qualitative parameters by number and percentage of patients.

Between educated and non-educated groups comparisons were assessed using variance analysis for quantitative criteria and $\mathrm{Chi}^{2}$ test for qualitative criteria. Within each group from M0 to M6 (6 month follow-up period), timeeffect analyses were performed by Student's paired $t$-test for quantitative variables and Mac Nemar's test for qualitative variables. All statistical tests were performed using a statistical significance threshold of 0.05 .

\section{Results}

Participants flow and baseline characteristics

Participants' flow chart is presented in Fig. 1. During the inclusion period, from November 2001 to end of March 2003, 96 primary care physicians enrolled 640 patients. It appears that the dropout rate was slightly higher for educated patients than for non-educated $(15.5 \%$ versus $11 \%$ ) but there was no clear reason to explain this difference.

Analysis for the primary outcome was performed for the 473 patients for whom a Framingham score could be calculated at both M0 and M6. Demographic characteristics at baseline were similar between educated and noneducated groups, and there was no statistical difference between the groups with regard to risk factor distribution (Table 1). 
Fig. 1 Flow chart of the participants included in the PEGASE study

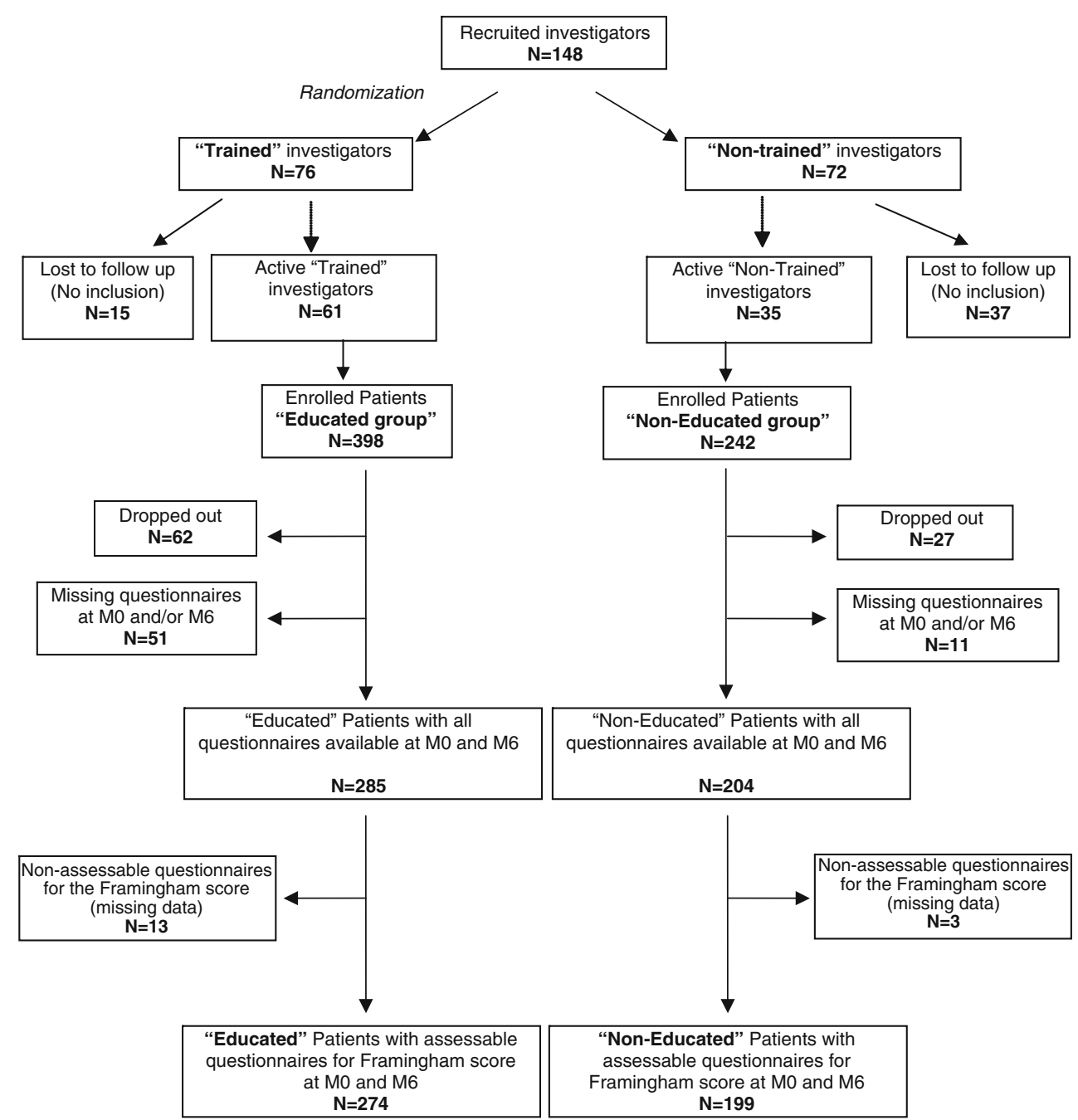

At baseline, $77 \%$ of patients were in a primary prevention category (I or II), whereas $23 \%$ were in category III (Table 1). Mean LDL-c levels at inclusion in patients belonging to category I, II and III were 155, 142 and $119 \mathrm{mg} / \mathrm{dL}$, respectively. Mean TC/HDL-c ratios were 4.75, 4.41 and 4.26 , respectively.

\section{Primary outcome}

In the intervention/educated group, the mean Framingham score decreased significantly between M0 and M6 (difference: $-0.658, p=0.016$ ) whereas in the non-educated group, the mean score did not change over the study period (difference: $+0.064, p=0.836$ ). However, the mean change between the two groups did not reach statistical significance $(p=0.08)$. At M0 and M6, the mean Framingham score was not significantly different between the educated and non-educated groups (13.6 \pm 8.48 versus $12.4 \pm 7.81, p=0.121$ and $13.0 \pm 8.21$ versus $12.5 \pm 8.19$, $p=0.542$ respectively).
Secondary outcomes

A significant difference between educated and noneducated groups was observed for LDL-c $(+8.0 \mathrm{mg} / \mathrm{dL}$; $t=2.16, p=0.032$ ), with no significant change over time in the intervention group compared with a significant increase in the control group $(+2.0 \mathrm{mg} / \mathrm{dL}, p=0.452$ versus $+10.0 \mathrm{mg} / \mathrm{dL}, p<10^{-3}$ ).

TC, drug compliance and cardio-protective diet score were significantly improved from M0 to M6 in the educated group, whereas they did not change in the control group (Table 2). In contrast, the number of patients with moderate to severe hypertension increased significantly by $10.2 \%(p=0.011)$ over time in the non-educated group only. Total cholesterol/HDL-c ratio did not vary significantly from M0 to M6 either in the educated group (4.57 \pm 1.4 to $4.45 \pm 2.17, p=0.12)$ or in the non-educated group $(4.24 \pm$ 1.32 to $4.18 \pm 1.47, p=0.4$ ). The additional criteria (fasting glycaemia, triglycerides, physical activity score, HDL-c, systolic BP, smoking) were not significantly modified in either group. 
Table 1 Socio-demographic and clinical characteristics of patients at baseline

\begin{tabular}{|c|c|c|c|c|}
\hline \multicolumn{2}{|l|}{ Characteristics } & \multirow{2}{*}{$\begin{array}{l}\text { Educated }(N=274) \\
167(60.9)\end{array}$} & \multirow{2}{*}{$\begin{array}{l}\text { Non-educated }(N=199) \\
117(58.8)\end{array}$} & \multirow{2}{*}{$\frac{p \text { value }}{0.704}$} \\
\hline Sex $n(\%)$ & Male & & & \\
\hline & Female & $107(39.1)$ & $82(41.2)$ & \\
\hline Age (years) & Mean+/-SD & $56.9 \pm 10.1$ & $58.1 \pm 12.0$ & 0.059 \\
\hline \multirow[t]{5}{*}{ Marital status, $n(\%)$} & Married & $187(69.3)$ & $139(70.2)$ & 0.067 \\
\hline & Cohabitation & $18(6.7)$ & $22(11.1)$ & \\
\hline & Single & $23(8.5)$ & $8(4.0)$ & \\
\hline & Widow & $15(5.6)$ & $16(8.1)$ & \\
\hline & Separated & $27(10.0)$ & $13(6.6)$ & \\
\hline \multirow[t]{4}{*}{ Education, $n(\%)$} & No education & $20(7.8)$ & $25(12.6)$ & 0.446 \\
\hline & Technical school & $133(52.0)$ & $97(48.7)$ & \\
\hline & Secondary education & $37(14.5)$ & $27(13.6)$ & \\
\hline & Higher education & $66(25.8)$ & $50(25.1)$ & \\
\hline \multirow{5}{*}{ Professional situation, $n(\%)$} & Working & $116(42.5)$ & $83(42.1)$ & 0.549 \\
\hline & Training & $-(-)$ & $1(0.5)$ & \\
\hline & Retired & $132(48.4)$ & $90(45.7)$ & \\
\hline & Non-working & $18(6.6)$ & $19(9.6)$ & \\
\hline & Unemployed & $7(2.6)$ & $4(2.0)$ & \\
\hline \multirow[t]{2}{*}{ Geographical environment, $n(\%)$} & Countryside & $66(24.4)$ & $56(28.1)$ & 0.395 \\
\hline & Urban environment & $204(75.6)$ & $143(71.9)$ & \\
\hline \multicolumn{5}{|l|}{ Primary prevention } \\
\hline Cat. I: LDL-c $>2.2 \mathrm{~g} / \mathrm{L}$ & & $42(15.3)$ & $32(16.1)$ & NS \\
\hline Cat. II: $1.6 \mathrm{~g} / \mathrm{L}<\mathrm{LDL}-\mathrm{c}<2.2 \mathrm{~g} / \mathrm{L}$ & & $161(58.8)$ & $129(64.8)$ & NS \\
\hline$+\mathrm{HBP}(\mathrm{BP}>140 / 90$ or treatment $)$ & & $85(31.0)$ & $76(38.2)$ & NS \\
\hline +Obesity $(\mathrm{BMI} \geq 30)$ & & $58(21.2)$ & $36(18.1)$ & NS \\
\hline+ Diabetes $(\mathrm{FGlc} \geq 1.26 \mathrm{~g} / \mathrm{L}$ or treatment $)$ & & $20(7.3)$ & $21(10.6)$ & NS \\
\hline +Smoking & & $52(19.0)$ & $47(23.6)$ & NS \\
\hline+ CVD familial history & & $58(21.2)$ & $41(20.6)$ & NS \\
\hline$+\mathrm{HDL}-\mathrm{C}<0.35 \mathrm{~g} / \mathrm{L}$ & & $7(2.6)$ & $12(6.0)$ & NS \\
\hline Secondary prevention (Cat. III) & & $71(25.9)$ & $38(19.1)$ & NS \\
\hline
\end{tabular}

FGlc fasting glycemia, $H B P$ high blood pressure

Quality of life (Table 3) was significantly improved after intervention in the educated group, with a significant difference between the mean change of the physical component score of the educated group and the noneducated group ( $+2.57, p=0.001$ vs $-0.5, p=0.356)$, as well as for several other characteristics (physical functioning, role-physical, general health and vitality). There was no significant difference in mental component score between the two groups.

Analysis according to patients' tertiles

An analysis of Framingham score reduction according to patients' tertiles within the educated group was performed. The objective was to analyze which patients would benefit most from the PEGASE program. The best responders, i.e. patients with a decrease in Framingham score of more than 1.9 points between M0 and M6, were compared with the other patients.

The baseline clinical characteristics of the "best responders" were significantly different from those of the other patients, with a higher Framingham score and a higher level of all major risk factors except for smoking (Table 4). There were more diabetic, and hypertensive patients but fewer smokers among the best responders than others $(8.6 \%$ vs $24.3 \%, p=0.002)$. They were of the same socio-economic background, with similar levels of education and lifestyle compared with the other patients.

\section{Discussion}

Our study demonstrated that the PEGASE education program has an effect on quality of life, dietary intake and LDL-c level of patients at high risk of CVD, after 6 months of intervention. However, this did not result in a significant change in the global CVD risk score between intervention and control groups.

Regarding the primary outcome in the PEGASE study, i.e. the Framingham score, this was a particularly difficult endpoint for an education program evaluation [33-36]. As our objective was to implement the PEGASE program in other centres, it was necessary to use strong validated criteria. We have chosen to use the Framingham score to 
Table 2 Delta changes in secondary criteria in educated and non-educated groups from M0 to M6

\begin{tabular}{|c|c|c|c|c|}
\hline \multirow[t]{2}{*}{ Characteristics } & \multicolumn{2}{|c|}{ Educated $(n=274)$} & \multicolumn{2}{|c|}{ Non-educated $(n=199)$} \\
\hline & $\begin{array}{l}\text { Change from } \\
\text { baseline }\end{array}$ & $\begin{array}{l}p \text {-value (M6 vs } \\
\text { M0) }\end{array}$ & $\begin{array}{l}\text { Change from } \\
\text { baseline }\end{array}$ & $\begin{array}{l}p \text {-value (M6 } \\
\text { vs M0) }\end{array}$ \\
\hline \multicolumn{5}{|l|}{ Framingham score parameters } \\
\hline Total cholesterol $(\mathrm{g} / \mathrm{L})$ & -0.0764 & 0.0006 & -0.034 & 0.246 \\
\hline HDL-c (g/L) & +0.0087 & 0.27 & +0.0038 & 0.70 \\
\hline $\mathrm{SBP}(\mathrm{mmHg})$ & -0.63 & 0.494 & +0.34 & 0.733 \\
\hline Smoking & $-13.7 \%$ & 0.065 & $-12.7 \%$ & 0.146 \\
\hline \multicolumn{5}{|l|}{ Auto-evaluated criteria } \\
\hline Total "cardio-protective diet" Score (from -22 to +29$)^{b}$ & +4.0 & $<10^{-3}$ & +0.0174 & 0.969 \\
\hline Physical activity score (from 5 to 27$)^{\mathrm{c}}$ & +0.214 & 0.190 & -0.03 & 0.842 \\
\hline Drug compliance score (lipid lowering drugs) $(0-100 \%)^{\mathrm{d}}$ & +8.84 & 0.032 & +0.52 & 0.874 \\
\hline
\end{tabular}

$S B P$ systolic blood pressure, $H D L-c$ high density lipoprotein

${ }^{a}$ Between-group analysis, $p$ : NS

${ }^{\mathrm{b}}$ Educated/non-educated $n=87 / 86$

${ }^{\mathrm{c}}$ Educated/non-educated $n=182 / 176$

${ }^{\mathrm{d}}$ Educated/non-educated $n=92 / 83$

display potential small modifications of the major risk factors that would not be significant if they were taken independently. The slight improvement of the Framingham score in this population in the educated group from baseline to 6 months could thus be due to improvements in TC and to a moderate improvement of each parameter contributing to the global score.

The improvement observed in LDL-c levels in the educated group may be the consequence of better drug compliance and a healthier diet, significantly improved by the PEGASE program. The improvement of the diet quality was mainly due to a greater consumption of fruit and vegetables by the educated patients (data not shown), which is known to be associated with a lower risk of CVD [37]. These results show that the education program was particularly efficient in changing patients' habits towards a more "cardioprotective" diet. The use of simple tools in the program allowed enhancement of patients' global motivation, which was essential for the success of the intervention.

Several randomized controlled trials have been conducted to evaluate multimodal intervention using counselling and education with or without pharmacological treatments in patients at high risk of CVD [38-44]; generally, these programs were found to have a favourable impact on CVD risk factors and related mortality. However, the type of educational intervention was seldom reported and many educational programs consisted of simple information passively received by the patient in forms of leaflets, videos, postal reminders, telephone calls or advices dispensed by health care providers [40, 45-49]. In contrast, the PEGASE program is a real therapeutic education program, in which patients had to play an active role by identifying their own health status and risk criteria with the help of the Photolanguage ${ }^{\circledR}$ method $[50,51]$, analyzing

Table 3 Changes in quality of life scores of educated versus non-educated patients from M0 to M6

\begin{tabular}{|c|c|c|c|c|}
\hline \multirow[t]{2}{*}{ SF-36 scales } & \multicolumn{2}{|l|}{ Educated $(n=221)$} & \multicolumn{2}{|l|}{ Non-educated $(n=188)$} \\
\hline & Change from baseline & $p$-value (M6 vs M0) ${ }^{\mathrm{a}}$ & Change from baseline & $p$-value (M6 vs M0) \\
\hline Physical functioning & +6.72 & $10^{-3}$ & -0.63 & 0.556 \\
\hline Role-physical & +7.91 & 0.002 & +1.08 & 0.656 \\
\hline Body pain & +2.76 & 0.09 & -0.95 & 0.567 \\
\hline General health & +2.81 & 0.005 & -0.64 & 0.579 \\
\hline Vitality & +3.43 & 0.002 & -1.47 & 0.222 \\
\hline Social functioning & +2.09 & 0.196 & +0.73 & 0.622 \\
\hline Role-emotional & +2.22 & 0.401 & +3.55 & 0.158 \\
\hline Mental health & +1.79 & 0.12 & +0.13 & 0.909 \\
\hline Mental component score & +0.53 & 0.457 & +0.69 & 0.307 \\
\hline Physical component score & +2.57 & $10^{-3}$ & -0.5 & 0.356 \\
\hline
\end{tabular}

${ }^{\mathrm{a}}$ Between group analysis, $p=\mathrm{NS}$ 
Table 4 Baseline characteristics of patients whose Framingham score mostly decreased from M0 to M6 compared to others

\begin{tabular}{|c|c|c|c|c|c|}
\hline \multirow[t]{2}{*}{ Characteristics at M0 } & \multirow{2}{*}{$\begin{array}{l}\text { Best respondent patients } \\
(N=93) \\
n(\%)\end{array}$} & \multirow{2}{*}{$\begin{array}{l}\text { Other patients } \\
(N=181) \\
n(\%)\end{array}$} & \multirow[t]{2}{*}{ Mean \pm SD } & \multirow[t]{2}{*}{ Mean \pm SD } & \multirow[t]{2}{*}{$p$ value } \\
\hline & & & & & \\
\hline Primary prevention Cat I & $13(14.0)$ & $29(16.0)$ & & & NS \\
\hline Primary prevention Cat II & $60(64.5)$ & $101(55.8)$ & & & NS \\
\hline+ Hypertension $(\mathrm{BP}>140 / 90$ or treatment $)$ & $36(38.7)$ & $49(27.1)$ & & & 0.049 \\
\hline+ Diabetes $(\mathrm{FGlc} \geq 1.26 \mathrm{~g} / \mathrm{L}$ or treatment $)$ & $11(11.8)$ & $9(5.0)$ & & & 0.039 \\
\hline+ Current smoking & $8(8.6)$ & $44(24.3)$ & & & 0.002 \\
\hline Secondary prevention Cat III & $20(21.5)$ & $51(28.2)$ & & & NS \\
\hline Framingham score & & & $18.3 \pm 7.5$ & $11.2 \pm 7.9$ & $<10^{-3}$ \\
\hline Age (years) & & & $59.5 \pm 8.9$ & $55.6 \pm 10.5$ & 0.002 \\
\hline $\mathrm{SBP}(\mathrm{mmHg})$ & & & $140.6 \pm 15.0$ & $128.23 \pm 12.4$ & $<10^{-3}$ \\
\hline $\mathrm{DBP}(\mathrm{mmHg})$ & & & $82.3 \pm 8.7$ & $76.6 \pm 8.9$ & $<10^{-3}$ \\
\hline Fasting glycemia $(\mathrm{g} / \mathrm{L})$ & & & $1.13 \pm 0.27$ & $1.01 \pm 0.21$ & $<10^{-3}$ \\
\hline Total cholesterol $(\mathrm{g} / \mathrm{L})$ & & & $2.40 \pm 0.52$ & $2.20 \pm 0.51$ & 0.003 \\
\hline $\operatorname{HDL}(\mathrm{g} / \mathrm{L})$ & & & $0.50 \pm 0.12$ & $0.54 \pm 0.18$ & 0.034 \\
\hline LDL-c $(\mathrm{g} / \mathrm{L})$ & & & $1.57 \pm 0.44$ & $1.38 \pm 0.42$ & 0.001 \\
\hline
\end{tabular}

FGlc fasting glycemia

their lifestyle behaviour and providing a personal plan for the improvement of one or several risk factors. Whether there is a significant difference between passive and active programs remains to be determined, since the results of existing studies are somewhat mixed; some active interventions resulted in no differences between groups [39], while some passive programs did show an increase in compliance with telephone based interventions [48]. However, contrary to other cardiovascular management programs $[43,44]$, the PEGASE program is applicable to all categories of patients at risk for CVD whether in primary or secondary prevention, making it more broadly applicable to the general CVD patient population.

PEGASE program has been shown to be more efficient in patients at the highest risk for CVD, a result consistent with those observed in other clinical trials: people at highest risk for CVD benefit most either from hypertension control or from cholesterol lowering interventions [38, 52]. However, good responders to PEGASE program smoked less frequently than other patients and smoking as a risk factor may be more difficult to modify than other conditions due to the addiction that tobacco induces. Evidence suggests that intensive smoking cessation programs (combinations of intensive counselling and followup with or without pharmacological intervention) can significantly increase both short- and long-term quit rates compared with minimal or no intervention [53-55]. Many patients believe that they can successfully quit smoking on their own, despite many having tried and failed in the past; [56] thus, patients need to be educated regarding the fact that smoking cessation programs can significantly increase their chances of long-term success.
There are several limitations to our study. The present study did not have sufficient power and/or period of follow-up to achieve a significant difference between the two study groups. Extension of the study may have revealed this significance, since the score improvement was already substantial after only 6 months of intervention. As shown in other studies [24, 57, $58]$, the benefits in terms of cardiovascular event reduction may occur over time and not in the early stages of an intervention program. Furthermore, behavioural changes require a long "step by step" process [20, 24]. The lack of significance in this study could also be explained by the lower number of evaluated patients at 6 months compared to that estimated in the study protocol, or by an underestimation of the initial CVD risk level taken for the primary hypothesis. As expected in this kind of open study evaluating an education program, the number of patients and physicians who dropped out was important. However, the withdrawal rate in the present study was $11 \%$ for the non-educated group and $15.5 \%$ for the educated group; this rate is similar to that of other studies $[37,56]$.

Another reason for the lack of significance could be the secondary motivation of both physicians and patients in the "non-educated" group, related to their participation in an educational program. Instead of a potential increase in this group, the global risk score did not change significantly. Knowing that their risk factors were going to be carefully monitored, both patients and physicians of the "noneducated" group may have been motivated to control these risk factors to a greater extent than normal; this phenomenon has been described in other studies [47]. Smoking, which decreased by the same extent (about 13\%) in both groups, clearly showed that the non-educated group had also 
made efforts to improve its habits. Finally, education strategies might be less effective in diseases such as hypercholesterolemia, which is usually perceived as a non-severe condition, than for other symptomatic diseases such as diabetes mellitus, which is recognized as a major risk factor.

In conclusion, we observed a significant improvement in the Framingham score in the educated group while there was no change in the non-educated group. However, the difference between groups did not reach statistical significance. This result might be explained by the attrition rate, resulting in only 473 evaluable patients instead of the 600 planned. Furthermore, most educational programs tend to evaluate the benefit on softer endpoints.

Obviously, more research is needed to find out the most effective strategy to use for hypercholesterolemic patients at risk for CVD. More specifically, there is a need to assess whether a specific approach (focused on a single risk factor such as hypercholesterolemia or a single behaviour such as dietary habit for example) leads to greater improvement in cardiovascular risk than a more global approach in which messages can be diluted or less well understood. Further research should probably focus on patients at the highest risk and with a low level of information. Indeed, conducting a trial which implies signed consent and rather strict rules is often associated with a selection bias towards the more motivated and educated patients.

The present study showed that a simple and wellconceived education program could have an impact on LDL-c levels, patients' health perception, quality of life and dietary intake via positive changes in the health care provider-patient dynamic. This study was carried out in real-life practice conditions, i.e. the physicians could adjust the treatments at their discretion and the patients could eat what they wanted as long as they followed the dietary advice. Supported by patients and physicians, the PEGASE program could thus easily be implemented and generalized in other centres.

Acknowledgements English language assistance for the preparation of this manuscript was provided by Sheridan Henness. This assistance was funded by AstraZeneca France.

\section{References}

1. Murray CJL, Lopez AD (eds). The global burden of disease: a comprehensive assessment of mortality and disability from diseases, injuries, and risk factors in 1990 and projected to 2020. Boston: Harvard School of Public Health; 1996

2. World Health Organization cardiovascular disease fact sheet [online]. URL: http://www.who.int/cardiovascular_diseases/en/. Accessed 19 December 2007.

3. Forrester JS, Merz CN, Bush TL, Cohn JN, Hunninghake DB, Parthasarathy S, et al. 27th Bethesda Conference: matching the intensity of risk factor management with the hazard for coronary disease events. Task Force 4. Efficacy of risk factor management. J Am Coll Cardiol 1996;27:991-1006.

4. Kita T. Coronary heart disease risk in Japan—an East/West divide. Eur Heart J. 2004;6:A8-11.

5. Gupta R, Sarna M, Thanvi J, Rastogi P, Kaul V, Gupta VP. High prevalence of multiple coronary risk factors in Punjabi Bhatia community: Jaipur Heart Watch-3. Indian Heart J. 2004;56:646-52.

6. Scandinavian Simvastatin Survival Study Group. Randomised trial of cholesterol lowering in 4444 patients with coronary heart disease: the Scandinavian Simvastatin Survival Study (4S). Lancet 1994;344:1383-9.

7. Shepherd J, Cobbe SM, Ford I, Isles CG, Lorimer AR, MacFarlane PW, et al. Prevention of coronary heart disease with pravastatin in men with hypercholesterolemia. N Engl J Med. 1995;333:1301-7.

8. Yusuf S, Hawken S, Ounpuu S, Dans T, Avezum A, Lanas F, et al. Effect of potentially modifiable risk factors associated with myocardial infarction in 52 countries (the INTERHEART study): case-control study. Lancet. 2004;364:937-52.

9. EUROASPIRE Study Group. EUROASPIRE. A European Society of Cardiology survey of secondary prevention of coronary heart disease: principal results. Eur Heart J. 1997;18:1569-82. Erratum in: Eur Heart J 1998; 19:356-357.

10. EUROASPIRE II Study Group. Lifestyle and risk factor management and use of drug therapies in coronary patients from 15 countries; principal results from EUROASPIRE II Euro Heart Survey Programme. Eur Heart J. 2001;22:554-72.

11. The Clinical Quality Improvement Network (CQIN) Investigators. Low incidence of assessment and modification of risk factors in acute care patients at high risk for cardiovascular events, particularly among females and the elderly. Am J Cardiol. 1995;76:570-3.

12. Ellerbeck EF, Jencks SF, Radford MJ, Kresowik TF, Craig AS, Gold JA, et al. Quality of care for Medicare patients with acute myocardial infarction. A four-state pilot study from the Cooperative Cardiovascular Project. JAMA. 1995;273:1509-14.

13. McLaughlin TJ, Soumerai SB, Willison DJ, Gurwitz JH, Borbas $\mathrm{C}$, Guadagnoli E, et al. Adherence to national guidelines for drug treatment of suspected acute myocardial infarction: evidence for undertreatment in women and the elderly. Arch Intern Med. 1996;156:799-805. Erratum in: Arch Intern Med 1996; 156:1920.

14. Frolkis JP, Zyzanski SJ, Schwartz JM, Suhan PS. Physician noncompliance with the 1993 National Cholesterol Education Program (NCEP-ATPII) guidelines. Circulation. 1998;98:851-5.

15. EUROASPIRE I and II Group. European Action on Secondary Prevention by Intervention to Reduce Events. Clinical reality of coronary prevention guidelines: a comparison of EUROASPIRE I and II in nine countries. Lancet. 2001;357:995-1001.

16. Sueta CA, Chowdhury M, Boccuzzi SJ, Smith SC Jr, Alexander $\mathrm{CM}$, Londhe A, et al. Analysis of the degree of undertreatment of hyperlipidemia and congestive heart failure secondary to coronary artery disease. Am J Cardiol. 1999;83:1303-7. Erratum in: Am J Cardiol 1999; 84:1143.

17. Kopjar B, Sales AE, Pineros SL, Sun H, Li YF, Hedeen AN. Adherence with statin therapy in secondary prevention of coronary heart disease in veterans administration male population. Am J Cardiol. 2003;92:1106-8.

18. House WC, Pendleton L, Parker L. Patients' versus physicians' attributions of reasons for diabetic patients' noncompliance with diet. Diabetes Care. 1986;9:434.

19. Riesen WF, Darioli R, Noll G. Lipid-lowering therapy: strategies for improving compliance. Curr Med Res Opin. 2004;20:165-73.

20. De Backer G, Ambrosioni E, Borch-Johnsen K, Brotons C, Cifkova R, Dallongeville J, et al. European Society of Cardiology Committee for Practice Guidelines. European guidelines on cardiovascular disease prevention in clinical practice: third joint 
task force of European and other societies on cardiovascular disease prevention in clinical practice (constituted by representatives of eight societies and by invited experts). Eur J Cardiovasc Prev Rehabil 2003;10:S1-10.

21. Pearson TA, McBride PE, Miller NH, Smith SC. 27th Bethesda Conference: matching the intensity of risk factor management with the hazard for coronary disease events. Task Force 8 . Organization of preventive cardiology service. J Am Coll Cardiol. 1996;27:1039-47.

22. Revell CC, Schroeder SA. Simplicity matters: using system-level changes to encourage clinician intervention in helping tobacco users quit. Nicotine Tob Res. 2005;7(Suppl 1):S67-9.

23. Ebrahim S, Davey Smith G. Systematic review of randomised controlled trials of multiple risk factor interventions for preventing coronary heart disease. BMJ. 1997;314:1666-74.

24. Ferrieres J, Durack-Bown I, Giral P, Chadarevian R, Benkritly A, Bruckert E. Patient education and patient at risk. A new approach in cardiology. Ann Cardiol Angeiol (Paris). 2006;55:27-31.

25. Prochaska JO, Di Clemente CC. Stages of change in the modification of problem behaviors. Prog Behav Modif. 1992;28:183-218.

26. WHO Working Group Report. Therapeutic Patient Education: Continuing education programmes for healthcare providers in the field of prevention of chronic diseases. Copenhagen, Denmark: WHO-Europe; 1998.

27. Durack-Bown I, Giral I, d'Ivernois JF, Bazin C, Chadarevian R, Benkritly A, et al. Patients' and physicians' perceptions and experience of hypercholesterolaemia: a qualitative study. Br J Gen Pract. 2003;53:851-7.

28. Brazier JE, Harper R, Jones NM, O'Cathain A, Thomas KJ, Usherwood T, et al. Validating the SF-36 health survey questionnaire: new outcome measure for primary care. BMJ. 1992;305:160-4.

29. Norman A, Bellocco R, Bergstrom A, Wolk A. Validity and reproducibility of self-reported total physical activity-differences by relative weight. Int J Obes Relat Metab Disord. 2001;25:682-8.

30. Laviolle B, Froger-Bompas C, Guilloc P, Sevestred A, Letelliere C, Pouchard M, et al. Relative validity and reproducibility of a 14-item semi-quantitative food frequency questionnaire for cardiovascular prevention. Eur J Cardiovasc Prev Rehabil. 2005;12:587-95.

31. Anderson KM, Wilson PWF, Odell PM, Kannel WB. An updated coronary risk profile: a statement for health professionals. Circulation. 1991;83:357-63.

32. Nguyen Phong Chau LD, Cazelles B, Segond P, PCV-Metra Group. Estimation of CHD risk in a French working population using a modified Framingham model.. J Clin Epidemiol. 1994;47:1353-64.

33. Thomsen TF, McGee D, Davidsen M, Jorgensen T. A crossvalidation of risk-scores for coronary heart disease mortality based on data from the Glostrup Population Studies and Framingham Heart Study. Int J Epidemiol. 2002;31:817-22.

34. D'Agostino RB Sr, Grundy S, Sullivan LM, Wilson P, CHD Risk Prediction Group 2001. Validation of the Framingham coronary heart disease prediction scores: results of a multiple ethnic groups investigation. JAMA. 2001;286:180-7.

35. Brindle P, Emberson J, Lampe F, Walker M, Whincup P, Fahey T, et al. Predictive accuracy of the Framingham coronary risk score in British men: prospective cohort study. BMJ. 2003;327:1267.

36. Empana JP, Ducimetiere P, Arveiler D, Ferrieres J, Evans A, Ruidavets JB, et al. Are the Framingham and PROCAM coronary heart disease risk functions applicable to different European populations? The PRIME Study. Eur Heart J. 2003;24:1903-11.

37. Bazzano LA, He J, Ogden LG, Loria C, Vupputuri S, Myers L, et al. Legume consumption and risk of coronary heart disease in US men and women. NHANES I epidemiologic follow-up study. Arch Intern Med. 2001;161:2573-8.
38. Ellingsen I, Hjermann I, Abdelnoor M, Hjerkinn EM, Tonstad S. Dietary and antismoking advice and ischemic heart disease mortality in men with normal or high fasting triacylglycerol concentrations: a 23-y follow-up study. Am J Clin Nutr. 2003;78:935-40.

39. Lichtman JH, Amatruda J, Yaari S, Cheng S, Smith GL, Mattera JA, et al. Clinical trial of an educational intervention to achieve recommended cholesterol levels in patients with coronary artery disease. Am Heart J. 2004;147:522-8.

40. Sartorio A, Lafortuna CL, Marinone PG, Tavani A, La Vecchia C, Bosetti C. Short-term effects of two integrated, non-pharmacological body weight reduction programs on coronary heart disease risk factors in young obese patients. Diabetes Nutr Metab. 2003;16:262-5.

41. Burke LE, Dunbar-Jacob J, Sereika S, Ewart CK. Development and testing of the Cholesterol-Lowering Diet Self-Efficacy Scale. Eur J Cardiovasc Nurs. 2003;2:265-73.

42. Mullen PD, Mains DA, Velez RA. Meta-Analysis of controlled trials of Cardiac Patient Education. Patient Educ Couns. 1992;19:143-62.

43. Mehta RH, Montoye CK, Gallogly M, Baker P, Blount A, Faul J, et al. Improving quality of care for acute myocardial infarction: The Guidelines Applied in Practice (GAP) Initiative. JAMA. 2002;287:1269-76.

44. Fonarow GC, Gawlinski A. Rationale and design of the Cardiac Hospitalization Atherosclerosis Management Program at the University of California Los Angeles. Am J Cardiol. 2000;85:10A-7A.

45. Tsuyuki RT, Johnson JA, Teo KK, Ackman ML, Biggs RS, Cave A, et al. Study of Cardiovascular Risk Intervention by Pharmacists (SCRIP): a randomized trial design of the effect of a community pharmacist intervention program on serum cholesterol risk. Ann Pharmacother. 1999;33:910-9.

46. Reid V, Barnes E, Daly L. Information sessions for outpatients referred to a hospital Nutrition and Dietetic Service for cholesterol lowering advice. J Hum Nutr Diet. 2001;15:281-6.

47. Ammerman AS, Keyserling TC, Atwood JR, Hosking JD, Zayed $\mathrm{H}$, Krasny C. A randomized controlled trial of a public health nurse directed treatment program for rural patients with high blood cholesterol. Prev Med. 2003;36:340-51.

48. Robinson JG, Conroy C, Wickemeyer WJ. A novel telephonebased system for management of secondary prevention to a lowdensity lipoprotein cholesterol $\leq 100 \mathrm{mg} / \mathrm{dl}$. Am J Cardiol. 2000;85:305-8.

49. Guthrie RM. The effects of postal and telephone reminders on compliance with pravastatin therapy in a national registry: results of the first myocardial infarction risk reduction program. Clin Ther. 2001;23:970-80.

50. Soignantes E. Photolanguage, a group psychotherapy. Soins Psychiatr. 1998;196:16-20.

51. Baptiste A, Belisle C. Photolangage ${ }^{\circledR}$. Prévention et Santé (dossier: 48 photos). Paris: Les éditions d'Organisation; 1994. p. 91-122.

52. Davey Smith G, Song F, Sheldon TA. Cholesterol lowering and mortality: the importance of considering initial level of risk. BMJ. 1993;306:1367-73.

53. Simon JA, Carmody TP, Hudes ES, Snyder E, Murray J, Simon $\mathrm{JA}$, et al. Intensive smoking cessation counseling versus minimal counseling among hospitalized smokers treated with transdermal nicotine replacement: a randomized trial. Am J Med. 2003;114:555-62.

54. Ranney L, Melvin C, Lux L, McClain E, Lohr KN. Systematic review: smoking cessation intervention strategies for adults and adults in special populations. Ann Intern Med. 2006;145:845-56.

55. Mohiuddin SM, Mooss AN, Hunter CB, Grollmes TL, Cloutier DA, Hilleman DE, et al. Intensive smoking cessation intervention 
reduces mortality in high-risk smokers with cardiovascular disease. Chest. 2007;131:446-52.

56. Sohn M, Stotts NA, Benowitz N, Christopherson D, Kim KS, Jang YS, et al. Beliefs about health, smoking, and future smoking cessation among South Korean men hospitalized for cardiovascular disease. Heart Lung. 2007;36:339-47.

57. The Multiple Risk Factor Intervention Trial Research Group. Mortality rates after 10.5 years for participants in the Multiple
Risk Factor Intervention Trial. Findings related to a priori hypotheses of the trial. JAMA. 1990;263:1795-801. Erratum in: JAMA 1990; 263:3151.

58. O’Malley PG, Kowalczyk C, Bindeman J, Taylor AJ. The impact of cardiovascular risk factor case management on the metabolic syndrome in a primary prevention population: results from a randomized controlled trial. J Cardiometab Syndr. 2006;1:6-12. 